\title{
Implicit stereotyping against people with disability
}

\author{
Odile Rohmer ${ }^{1}$ and Eva Louvet ${ }^{1}$
}

\begin{abstract}
Focusing on the two fundamental dimensions underlying stereotype content (warmth/competence), the major aim of the present research was to test implicit stereotyping toward persons with disability. We hypothesized that persons with disability are associated with less warmth than persons without disability and with less competence, especially when a competence-relevant context is activated (work context). Three experimental studies were conducted using two different priming paradigms: conceptual priming (Study 1) and evaluative priming (Studies 2 and 3). In Study 3, context (work vs. control) was introduced as an additional factor. Our results showed that persons with disability were systematically associated with less warmth than persons without disability, and with less competence when priming a work context. These results provide a more comprehensive understanding of discriminatory behaviors toward people with disability, despite legislation promoting equal rights.
\end{abstract}

\section{Keywords}

competence, disability, priming, stereotype, warmth

Paper received 15 May 2015; revised version accepted 19 January 2016.

Over the past two decades, a growing body of research on intergroup relations has documented that prejudiced attitudes and stereotyping can no longer be fully captured using traditional selfreported measures due to their sensitivity to normative pressures. Given societal pressures against discrimination, people may be reluctant to report negative evaluations of marginalized groups, or cannot accurately identify them by means of introspection (Devine, 1989; Fazio, Jackson, Dunton, \& Williams, 1995). Accordingly, researchers developed a number of new measurement techniques less susceptible to normative constraints, which promise to assess attitudes and stereotyping outside of the individual's control and awareness. A large number of studies indicated implicit negative evaluations of minorities that did not appear at an explicit level, most of them focusing on racism (Devine, 1989; Dovidio, Kawakami, Johnson, Johnson, \& Howard, 1997; Fazio et al., 1995; Wittenbrink, Judd, \& Park, 2001). The purpose of the present research was to explore implicit attitudes and stereotyping toward persons with disability, a strongly normatively protected group, rarely investigated in this area.

${ }^{1}$ University of Strasbourg, France

Corresponding author:

Odile Rohmer, University of Strasbourg, 12, rue Goethe, F-67000 Strasbourg, France.

Email: odile.rohmer@unistra.fr 


\section{Disability Prejudice and Stereotypes}

Persons with disability are the subject of considerable discrimination, especially when it comes to employment. Many companies do not expressly include persons with disabilities in their workplace diversity policies (Ball, Monaco, \& Schmeling, 2005), and employers continue to express reluctance to hire these persons (Bayle, 2002). For example, an experimental study conducted on a representative sample of more than 2,000 French companies indicated that able-bodied applicants were 1.8 (high qualification) to 3.2 (modest qualification) times more likely to receive a favorable response than their counterparts presented with a physical disability (Ravaud, Madiot, \& Ville, 1992). In order to combat this discrimination, progressive legislation has been implemented since the 1990s to promote equal rights for individuals with disability. In France, the Law of February 11, 2005 prohibits an employer from denying an otherwise qualified person employment or advancement solely on the basis of their disability. This law requires companies with more than 20 employees to fill a minimum of $6 \%$ of their jobs with workers with a disability; employers have also to provide practical and effective measures to adapt the workplace to the disability (Winance, Ville, \& Ravaud, 2007). However, despite this legislation, the gap in employment rates between persons with and without disabilities remains vast (Boman, Kjellberg, Danermark, \& Boman, 2015; Lo \& Ville, 2013; Watermeyer, 2012; World Health Organization [WHO], 2011). For example, in France, only half of the companies comply with the law, and the unemployment level for people with a disability remains the double of that of the general population. ${ }^{1}$

Negative behaviors against persons with disability in the workplace could be explained by negative attitudes and stereotypical beliefs toward these persons including perception of them as dependent, incompetent, unemployable, passive, and weak (Colella, De Nisi, \& Varma, 1998; Fichten \& Amsel, 1986; Gouvier, Sytsma-Jordan, \& Mayville, 2003; Louvet, 2007; Louvet, Rohmer,
\& Dubois, 2009; Nario-Redmond, 2010; Ozawa \& Yaeda, 2007). However, it has also been shown that stereotypical beliefs about persons with disability are not necessarily negative. Persons with disability are regularly described as courageous, heroic, hardworking, persistent, conscientious, honest, moral, and friendly (Bell \& Klein, 2001; Christman \& Slaten, 1991; Fichten \& Amsel, 1986; Kurita \& Kusumi, 2009; Louvet \& Rohmer, 2010; Nario-Redmond, 2010; Rohmer \& Louvet, 2011; Weinberg, 1976).

These ambivalent judgments toward persons with disability are in line with the theoretical framework of the stereotype content model (SCM) developed by Fiske and her colleagues (Cuddy, Fiske, \& Glick, 2007; Cuddy, Glick, \& Beninger, 2011; Fiske, Cuddy, Glick, \& Xu, 2002). According to this model, most social groups are not uniformly evaluated along a single "good/ bad" dimension, but along two fundamental dimensions labeled as warmth and competence. Warmth refers to the appraisal of others' motives and includes social and moral qualities (warm, likable, friendly, honest, etc.); competence refers to the appraisal of others' ability to effectively enact their motives and includes intellectual and motivational qualities (intelligent, capable, skillful, ambitious, etc.). Abundant research on group perception has demonstrated that most stereotypes are of a mixed nature, including ambivalent warmth-competence combinations: those groups seen as high on one dimension are usually seen as low on the other. Furthermore, group placement along these two dimensions is predicted by social structure, such that high-status groups appear more competent than low-status groups. In line with the mixed stereotype hypothesis, these groups are nevertheless often stereotyped as warm (Cambon, Yzerbyt, \& Yakimova, 2014; Cuddy et al., 2007; Fiske et al., 2002; Oldmeadow \& Fiske, 2010). Like most low-status groups, such as elderly people or housewives, people with disability have been consistently shown to be stereotyped as warm but incompetent, regardless of the nature of impairment (Cuddy et al., 2007; Fiske et al., 2002; Louvet et al., 2009; Rohmer \& Louvet, 2011). 
Negative evaluations toward persons with disability on competence can help explain, justify, and maintain social inequalities insofar as incompetence is perceived as a valid basis for discrimination (Nario-Redmond, 2010; Oldmeadow \& Fiske, 2010). However, overtly negative attitudes toward persons with disability are unacceptable in our society, because these persons are a strongly normatively protected group (Crandall, Eshleman, \& O’Brien, 2002; Dambrun \& Guimond, 2004). Consequently, positive evaluations on warmth could stem from an overcompensation strategy based on the motivation to appear unprejudiced. If these positive evaluations on warmth are deliberately endorsed, they would not manifest themselves when examining automatically activated evaluations, assumed to be outside of awareness and intentional control (Devine, 1989; Dovidio et al., 1997; Fazio, 2001; Greenwald \& Banaji, 1995; Wittenbrink \& Schwarz, 2007).

\section{Implicit Attitudes Toward Persons With Disability}

Although explicit attitudes and beliefs about persons with disability do not reflect uniform antipathy, implicit attitudes toward these persons are generally negative. For example, Pruett and Chan (2006) developed the Disability Attitude Implicit Association Test (DA-IAT), and showed that congruent associations (disability-negative and nondisabled-positive) occurred more frequently than incongruent associations (disability-positive and nondisabled-negative). These implicit attitudes were not related to an explicit attitude measure. These results have been replicated in multiple studies demonstrating that participants were faster to associate pictures or words referring to disability with negative words and nondisabled labels with positive words (Chen, Ma, \& Zhang, 2011; Dionne, Gainforth, O’Malley, \& Latimer-Cheung, 2013; Enea-Drapeau, Carlier, \& Huguet, 2012; Kurita \& Kusumi, 2009; Peris, Teachman, \& Nosek, 2008; Robey, Beckley, \& Kirschner, 2006). However, the IAT paradigm seems to violate one of the fundamental features of automatic procedures, the controllability: participants may become aware of what is assessed during the task (Dijksterhuis \& Bargh, 2001; Oswald, Mitchell, Blanton, Jaccard, \& Tetlock, 2013). For example, Thomas, Vaughn, and Doyle (2007) found evidence of socially desirable responding in their IAT studies measuring attitudes toward specific disability categories.

Negative implicit attitudes toward people with disability have also been highlighted using sequential priming procedures specifically designed to assess automatic associations between social categories and attributes without conscious awareness or controllability through the use of subliminal primes, backwards masks, or short stimuli onset asynchrony between primes and targets (Boccato, Cortes, Demoulin, \& Leyens, 2007; de Wit \& Kinoshita, 2014; Neely, 1977). For example, a disability prime associated to mental illness ("crazy") facilitated identification of stereotypical negative words (e.g., "dangerous," "irresponsible"), demonstrating implicit negative stereotyping, whereas individuals exhibited a positive bias toward persons with disability in their self-reported attitudes (Rüsch, Corrigan, Todd, \& Bodenhausen, 2011). In the same vein, priming participants with disability (pictogram of a person in a wheelchair) inhibited identification of positive characteristics (e.g., friendly, efficient, intelligent, nice), whereas the expected mixed pattern (warm but incompetent) was observed at an explicit level (Rohmer \& Louvet, 2012).

\section{Overview and Hypotheses}

The first aim of the present research was to examine how competence and warmth were implicitly associated to disability, using two different sequential priming procedures classically used in the literature to measure prejudice and stereotyping, conceptual and evaluative priming (Wittenbrink et al., 2001; Wittenbrink \& Schwarz, 2007). Our hypothesis was that incompetence generally associated with disability on an explicit level would also manifest itself on an implicit level. Insofar as competence is specifically relevant in a work context, we further hypothesized 
that persons with disability would be strongly associated with a lack of competence, when this context is activated. Moreover, we hypothesized that persons with disability would not be implicitly associated with warmth as consistently highlighted on an explicit level in line with the SCM. First, research using free response methodology showed that, contrary to incompetence, warmth is not spontaneously associated with the disability stereotype (Nario-Redmond, 2010). Second, positive warmth ratings observed on an explicit level could stem from an overcompensation strategy based on the motivation to appear unprejudiced (Cambon et al., 2014). If these positive evaluations on warmth are deliberately endorsed, they would not manifest themselves when examining automatically activated evaluations, assumed to be outside of awareness and intentional control. More precisely, our hypotheses were as follows: (H1) Positive traits would be recognized or evaluated slower following the disability prime than following the without-disability prime, whereas negative traits would be recognized or evaluated faster (general antipathy). (H2) Positive competence traits would be recognized or evaluated slower following the disability prime than following the without-disability prime, whereas negative competence traits would be recognized or evaluated faster (derogation on competence). (H3) Positive warmth traits would be recognized or evaluated slower following the disability prime than following the without-disability prime, whereas negative warmth traits would be recognized or evaluated faster (derogation on warmth). Competence and warmth were considered separately for two major reasons: first, competence and warmth are two independent dimensions to describe the stereotype content (Fiske et al., 2002); second, persons with disability are generally explicitly stereotyped as incompetent but warm. Our purpose was to show that this mixed stereotype would not manifest itself on an implicit level. In a complementary way, we aimed to test these three hypotheses when considering separately negative and positive items in order to test whether the expected devaluation of persons with disability was based on facilitation of negative items and/or inhibition of positive ones. Finally, we expected the same pattern of results when considering only the disability prime condition. More precisely, our hypotheses were as follows: (H1a) positive traits would be recognized or evaluated slower than negative ones; (H2a) positive competence traits would be recognized or evaluated slower than negative ones; $(\mathrm{H} 3 \mathrm{a})$ positive warmth traits would be recognized or evaluated slower than negative ones. Insofar as there is no stereotype content associated to able-bodied persons, we expected no differences between negative and positive items in the without-disability prime condition (Rohmer \& Louvet, 2009).

\section{Studies 1 and 2}

Building on the stereotype content model (Fiske et al., 2002), the main purpose of the first two studies was to analyze implicit stereotyping toward people with disability, using two different priming procedures widely used in the literature (Wittenbrink et al., 2001), conceptual (Study 1) and evaluative (Study 2) priming.

\section{Method}

Participants. Participants were 84 students, 46 men and 38 women (mean age $=22.86$ years; $S D$ $=3.45$ ) in Study 1, and 89 students, 56 men and 33 women (mean age $=20.81$ years; $S D=3.98$ ) in Study 2. All participants were French speaking, had normal or corrected-to-normal vision, and participated on a voluntary basis without financial compensation. None of them self-reported any disability. Data from three participants were excluded from the analyses in Study 2 due to a large number of missing values or to extremely slow responses.

Measures. In Study 1, implicit stereotyping was measured following the conceptual priming procedure used by Rohmer and Louvet (2012). Participants were first very briefly presented with priming stimuli. The primes involved symbolic pictures of a person with disability (the international disability pictogram of a person in a wheelchair) or without 
a disability (the international pedestrian pictogram), generally used in research on implicit attitudes toward persons with disability (Dionne et al., 2013; Pruett \& Chan, 2006). These primes were tested in a previous research, showing that the international disability pictogram was unanimously associated to disability ("disability," "disabled," "a handicapped person," etc.), whereas the international pedestrian pictogram evoked terms like "a person," "somebody who is walking," "a pedestrian," etcetera (Rohmer \& Louvet, 2012). ${ }^{2}$ In order to obtain baseline responses, a neutral prime condition was introduced (a square). Each prime was followed by a target stimulus requiring a lexical decision (word/no word). In Study 2, the material was the same, but stereotyping was measured following a simplified version of the evaluative priming paradigm (Fazio et al., 1995; Wittenbrink et al., 2001): participants had to judge for the evaluative connotation (good/bad) of the target stimulus. In both studies, the target stimuli were the same 16 traits, eight from each dimension (competence and warmth), four positive (high on competence or warmth) and four negative (low on competence or warmth). The nonwords used in Study 1 were eight pronounceable anagrams of the traits. The target stimuli were fully crossed with the three primes, and the order was randomized for each participant. To identify equally positive and negative traits denoting warmth and competence, we conducted a pilot study. Fifty-nine participants judged the valence of 30 traits on an evaluation scale ranging from -3 (extremely negative) to +3 (extremely positive). These traits were selected from research on the fundamental dimensions of social judgment (e.g., Fiske et al., 2002; Kervyn, Yzerbyt, Judd, \& Nunes, 2009; Louvet et al., 2009). The results allowed us to select four positive warmth and four positive competence traits in such a way that there was no difference between the mean warmth and the mean competence score, $t(58)=$ $0.97 ; p=.34$. In the same way, we selected four negative items for each dimension in such a way that there was no difference between the mean warmth and the mean competence score, $t(58)=$ $-0.65 ; p=.52$. The four positive warmth traits (translated from French) were: warm, nice, friendly, and likable. The four negative warmth items were: bad, selfish, bypocritical, and liar. The four positive competence traits were: competent, capable, intelligent, and efficient. The four negative competence traits were: incompetent, inefficient, unable, and disrupted.

Response latency measures were calculated relative to the neutral prime: for each adjective, the response latency following one or the other categorical prime (person with or without a disability) was subtracted from the response latency following the neutral prime. Larger values indicate greater response facilitation because of the specific categorical prime. In line with literature, the stronger the mental association between the prime and target adjective, the higher the facilitation score will be.

Procedure. The study was introduced to participants as an investigation on "how people visually recognize words" in Study 1, and on "judgmental accuracy" in Study 2. Participants were tested individually. The stimuli were presented on a monitor situated approximately $50 \mathrm{~cm}$ from the participant. During the administration of the task, participants were asked to focus on a fixation cross presented in the center of the screen for 1,000 ms. This point was followed by the prime, stimulus display was synchronized to the screen refresh rate $(17 \mathrm{~ms})$. Prime size was precisely $5 \mathrm{~cm} \times 5 \mathrm{~cm}$. Then, the prime was substituted by a backward mask (a geometrical figure) for $250 \mathrm{~ms}$ to prevent conscious identification of the prime. Finally, a target adjective was presented for $250 \mathrm{~ms}$ in white 18-point Arial font on a black background. In Study 1, participants had to decide as quickly and as accurately as possible whether the target stimulus was a word or not, by pressing the right (labeled "word") or left (labeled "non-word") arrows on the keyboard. In Study 2, participants had to decide as quickly and as accurately as possible, whether the target stimulus made them think of something positive and good or negative and bad, by pressing the "plus" or "minus" keys on the keyboard (Wittenbrink et al., 2001). Three interstimuli periods $(250,350$, and $450 \mathrm{~ms}$ ) were used and presented randomly to minimize anticipatory responses. Before 
Table 1. Studies 1 and 2. Mean response facilitation (in milliseconds) as a function of dimension (warmth and competence), trait valence (positive or negative), and prime (with and without disability).

\begin{tabular}{llllllr}
\hline & & \multicolumn{2}{l}{ With disability } & & \multicolumn{2}{l}{ Without disability } \\
& & Competence & Warmth & & Competence & Warmth \\
\hline Conceptual & Positive & -11.78 & -18.49 & & 0.00 & 2.22 \\
task (Study 1) & Negative & 1.51 & 7.73 & & 12.08 & -3.99 \\
Evaluative & Positive & -5.27 & -15.86 & & 2.77 & 0.71 \\
task (Study 2) & Negative & -3.71 & 8.80 & & 9.78 & 2.61 \\
\hline
\end{tabular}

Table 2. Contrast weights used in the three studies.

\begin{tabular}{|c|c|c|c|c|c|}
\hline & & \multicolumn{2}{|l|}{ With disability } & \multicolumn{2}{|c|}{ Without disability } \\
\hline & & Competence & Warmth & Competence & Warmth \\
\hline \multicolumn{6}{|l|}{ Contrast 1: } \\
\hline \multirow[t]{2}{*}{ General antipathy } & Positive & -1 & -1 & +1 & +1 \\
\hline & Negative & +1 & +1 & -1 & -1 \\
\hline \multicolumn{6}{|l|}{ Contrast 2: } \\
\hline \multirow{2}{*}{$\begin{array}{l}\text { Derogation on } \\
\text { competence }\end{array}$} & Positive & -1 & 0 & +1 & 0 \\
\hline & Negative & +1 & 0 & -1 & 0 \\
\hline \multicolumn{6}{|l|}{ Contrast 3: } \\
\hline \multirow{2}{*}{$\begin{array}{l}\text { Derogation on } \\
\text { warmth }\end{array}$} & Positive & 0 & -1 & 0 & +1 \\
\hline & Negative & 0 & +1 & 0 & -1 \\
\hline
\end{tabular}

responding to the experimental trials, 10 practice trials were presented. To ensure that participants were not aware of the primes, they were asked after completing the experimental task, whether they noticed anything on the screen between the fixation cross and the geometrical figure. None of the participants was able to identify the pictures.

\section{Results}

Results were based only on correct responses. Errors (categorization of a word as a nonword in Study 1, positive evaluation of a negative word or negative evaluation of a positive word in Study 2) and extreme outliers (response latencies beyond two standard deviations below or above mean score for each item) were recoded as missing values (below 10\% of values were recoded as missing). In our data analysis, we created average facilitation scores for the four positive and the four negative warmth and competence-related adjectives following each prime. Following recent recommendations (Cumming, 2014), we tested planned contrasts based on our theoretical assumptions, rather than reporting omnibus analyses of variance. All means are given in Table 1. On the basis of facilitation differences as a function of prime (with disability vs. without disability), dimension (competence vs. warmth), and valence (positive vs. negative), all factors varying within participants, we computed several contrasts of interest, presented in Table 2. The first contrast (C1) aimed to test $\mathrm{H} 1$ and captures generalized antipathy, regardless of the dimension considered. The two following contrasts aimed to test $\mathrm{H} 2$ and $\mathrm{H} 3$, and capture stereotype content, examining separately competence (C2) and warmth (C3). Variants of these three contrasts examine whether results are similar when considering separately negative and positive items. Finally, we analyzed data separately for 
the disability prime condition and the [AQ: 1] without-disability prime condition in order to test $\mathrm{H} 1 \mathrm{a}, \mathrm{H} 2 \mathrm{a}$, and $\mathrm{H} 3 \mathrm{a}$.

Study 1. In line with H1, the first contrast (C1) suggested generalized antipathy toward persons with disability, $F(1,83)=5.56, p<.03$. However, this prejudice appeared only for positive traits: these traits were more facilitated following the without-disability prime than following the disability prime, $F(1,83)=9.45, p<.003$, whereas no prime effect was observed for negative items. In line with H1a, negative items showed marginally significant larger facilitation than positive items following the disability prime, $F(1,83)=3.83, p<$ .07 , whereas, as expected, the difference between negative and positive items was not significant following the without-disability prime. The two following contrasts, examining separately competence (C2) and warmth (C3), showed that this overall antipathy effect was attributable solely to warmth, $F(1,83)=5.84, p<.02$, supporting H3 but infirming $\mathrm{H} 2$. In the same way as for general prejudice, derogation on warmth appeared only for positive traits: these traits were more facilitated following the without-disability prime than following the disability prime, $F(1,83)=13.91$, $p<.0004$, whereas no prime effect was observed for negative items. Finally, in line with $\mathrm{H} 3 \mathrm{a}$, negative warmth items showed larger facilitation than positive warmth items following the disability prime, $F(1,83)=5.84, p<.02$, whereas again, as expected, the difference between negative and positive items was not significant following the without-disability prime. Contrary to $\mathrm{H} 2 \mathrm{a}$, no effect was found for competence.

Study 2. Concerning the first contrast (C1), the cell means suggested the same pattern of results as Study 1, although this general contrast failed to reach a conventional level of significance, $F(1,88)=1.33, p=.25$. However, this generalized prejudice was observed when focusing on positive traits: these traits were more facilitated following the without-disability prime than following the disability prime, $F(1,88)=5.53, p<$ .03 , whereas no prime effect was observed for negative items. In sum, these results partially supported H1. Moreover, in line with H1a, negative items showed larger facilitation than positive items following the disability prime, $F(1$, $88)=4.04, p<.05$, whereas again, as expected, the difference between negative and positive items was not significant following the withoutdisability prime. Again, the two following contrasts (C2 and C3) indicated that this overall antipathy was attributable to warmth, $F(1,88)=$ $3.76, p<.05$, supporting H3 but infirming H2. Again, this derogation on warmth appeared only for positive traits: these traits were more facilitated following the without-disability prime than following the disability prime, $F(1$, $88)=4.77, p<.04$, whereas no prime effect was observed for negative items. Finally, in line with $\mathrm{H} 3 \mathrm{a}$, negative warmth items showed larger facilitation than positive warmth items following the disability prime, $F(1,88)=6.94, p<.01$, whereas the difference between negative and positive items was again not significant following the without-disability prime. Contrary to $\mathrm{H} 2 \mathrm{a}$, no effect was found for competence.

\section{Discussion}

Results from these first two studies were quite consistent. First, our results supported H1 and $\mathrm{H} 3$ for positive items: positive warmth items were systematically recognized (Study 1) and evaluated (Study 2) slower following the disability prime than following the without-disability prime. Second, the same pattern of results appeared following the disability prime, confirming H1a and H3a: positive warmth items were recognized (Study 1) and evaluated (Study 2) slower than negative ones. These results are largely supportive of previous results suggesting negative evaluations toward persons with disability at an implicit level (Chen et al., 2011; Dionne et al., 2013; EneaDrapeau et al., 2012; Kurita \& Kusumi, 2009; Peris et al., 2008; Rohmer \& Louvet, 2012). They also corroborate the idea that positive warmth ratings generally observed on an explicit level (Fiske et al., 2002; Rohmer \& Louvet, 2011) could stem from pressures towards nondiscrimination 
leading individuals to compensate negative evaluations on competence by positive evaluations on warmth (Cambon et al., 2014).

The absence of effect for negative traits could be explained by the fact that people are less likely to use negative traits to describe individuals or groups (Fiske et al., 2002; Wade \& Brewer, 2006). Consequently, negative traits are less familiar and more difficult to automatically activate from memory. The expected absence of effect for the without-disability prime condition may be due to the fact that "persons without disability" cannot be considered as a meaningful categorical label because they have no informational value in person perception (Rohmer \& Louvet, 2009). Research comparing explicit judgments toward persons with and without disability suggested that "nondisabled" or "able bodied" are rated neither high nor low on warmth and competence. Referring to this "group" makes sense only in comparison to “disabled" (Rohmer \& Louvet, 2011).

Another intriguing issue concerns the absence of implicit negative evaluation of persons with disability on competence, infirming H2. This finding could be explained by the idea that competence may be more context-dependent than warmth. Recent work on the two fundamental dimensions of social judgment suggested that people in different countries agreed more on the meaning of warmth traits than on the meaning of competence traits (Abele, Uchronski, Suitner, \& Wojciszke, 2008; Ybarra et al., 2008). In a similar way, Abele and Bruckmüller (2011) showed that participants were faster to recognize, categorize, or infer warmth items than competence items, suggesting that warmth items are preferentially processed on early stages of information processing. These authors hypothesized that warmth dominates social judgment as the default in most situations, whereas the relevance of competence may depend on the specific context at hand. Insofar as competence is especially relevant in a work context, we expected that persons with disability would be associated with a lack of competence when this context is activated. The purpose of Study 3 was to examine this hypothesis.

\section{Study 3}

The main purpose of Study 3 was to further examine implicit stereotype content toward people with disability by introducing context (competence-relevant vs. control) as an additional independent variable. In line with results obtained in Studies 1 and 2, without specific context (control), we expected general prejudice (H1 and H1a) as well as derogation on warmth (H3 and H3a). More interestingly, when a competence-relevant context is activated, we expected general prejudice (H1 and $\mathrm{H} 1 \mathrm{a})$, derogation on warmth ( $\mathrm{H} 3$ and $\mathrm{H} 3 \mathrm{a})$, and derogation on competence (H2 and H2a).

\section{Method}

Participants. One hundred and sixty-five French speaking students from various areas (85 men and 80 women), mean age 21.40 years ( $S D=$ 2.48) were recruited on campus to participate in this experiment without financial compensation. Again, all participants had normal or correctedto-normal vision, and none of them presented any disability.

Material and procedure. Implicit stereotyping was measured using the same evaluative priming paradigm as that used in Study 2. In order to activate a competence-relevant context versus control condition, participants responded to an ostensible unrelated questionnaire concerning "work" versus "society" before completing the evaluative task. They were asked to rate 12 work-related versus 12 society-related statements by indicating the extent to which they agree to these statements on 4-point scales. For example, "work allows to earn money," "work involves responsibilities," versus "in our society it is important having somewhere to live," "in our society it is important respecting the freedom of others." These questions were selected from a pilot study so that they included topics participants strongly associated with "work" versus "society." As the purpose of this questionnaire was simply to prime a specific versus a general context, the results were not analyzed. 
Table 3. Study 3. Mean response facilitation (in milliseconds) as a function of context (work and control), dimension (warmth and competence), trait valence (positive or negative), and prime (with and without disability.

\begin{tabular}{|c|c|c|c|c|c|}
\hline & & \multicolumn{2}{|l|}{ With disability } & \multicolumn{2}{|c|}{ Without disability } \\
\hline & & Competence & Warmth & Competence & Warmth \\
\hline \multirow[t]{2}{*}{ Control condition } & Positive & 1.63 & -9.93 & 10.72 & 16.58 \\
\hline & Negative & -11.20 & 26.51 & 0.18 & 6.03 \\
\hline \multirow[t]{2}{*}{ Work condition } & Positive & -19.50 & -17.34 & 11.39 & 12.83 \\
\hline & Negative & 21.12 & 16.35 & 7.36 & 23.24 \\
\hline
\end{tabular}

\section{Results}

Results were based only on correct responses. Errors and extreme outliers were recoded as missing values (below 10\%). Again, we collapsed across the five adjectives given each prime on each dimension and valence. In line with our hypotheses, we present the results for each of the two experimental conditions (control condition and work condition) examining the same contrasts as the ones defined in Studies 1 and 2 (see Table 2). All means are given in Table 3.

Control condition. Data revealed a pattern of results similar to those obtained in Studies 1 and 2. In line with H1, the first contrast (C1) suggested generalized antipathy toward persons with disability, $F(1,84)=4.72, p<.04$. Again, this prejudice appeared only for positive items: these items were more facilitated following the without-disability prime than following the disability prime, $F(1,84)=6.08, p<.02$. No prime effect was observed for negative items. However, contrary to $\mathrm{H} 1 \mathrm{a}$, this general prejudice did not reach significance when focusing on the disability prime condition. The two following contrasts, examining separately competence (C2) and warmth (C3), showed that this overall antipathy effect was attributable solely to warmth, $F(1,84)=8.08, p<$ .006 , supporting H3. Again, derogation on warmth appeared for positive traits: these traits showed larger facilitation following the withoutdisability prime than following the disability prime, $F(1,84)=6.80, p<.02$. The reversed pattern of results was marginally significant for negative warmth items, $F(1,84)=3.03, p<.09$.
Finally, in line with $\mathrm{H} 3 \mathrm{a}$, negative warmth items showed larger facilitation than positive ones following the disability prime, $F(1,84)=5.21, p<$ .03 , whereas this difference was not significant following the without-disability prime. As expected, and as observed in Studies 1 and 2, no effect was found for competence. In sum, these results replicated those obtained in Studies 1 and 2. Persons with disability were specifically associated with negative implicit evaluations on warmth.

Work condition. Data obtained when priming a work context showed a different pattern of results. The first contrast again supported $\mathrm{H} 1$ and revealed generalized antipathy toward persons with disability, $F(1,79)=12.68, p<.0007$. Again, this prejudice appeared only for positive traits, $F(1,79)=$ 15.86, $p<.0002$. In line with H1a, the difference between negative and positive items was significant when considering the disability prime, $F(1$, $79)=15.43, p<.0002$, but not when considering the without-disability prime. The two following contrasts (C2 and C3) showed that this overall antipathy effect was this time attributable mainly to competence, $F(1,79)=11.86, p<.001$, supporting H2. This derogation on competence appeared for positive traits: these traits showed larger facilitation following the without-disability prime than following the disability prime, $F(1,79)=8.95, p<.004$. The reversed pattern of results was marginally significant for negative items, $F(1,79)=3.17, p<.08$. Finally, in line with $\mathrm{H} 2 \mathrm{a}$, negative competence items showed larger facilitation than positive ones following the disability prime, $F(1,79)=12.74, p<$ .0007 , whereas this difference was not significant following the without-disability prime. Concerning 
warmth, the expected derogation effect $(\mathrm{H} 3)$ failed to reach significance, $F(1,79)=2.65, p=.11$. However, this effect appeared when considering only positive warmth items, $F(1,79)=7.04, p<$ .01. Finally, in line with $\mathrm{H} 3 \mathrm{a}$, the difference between negative and positive warmth items was again significant when considering the disability prime, $F(1$, $79)=5.80, p<.02$.

\section{Discussion}

Taken together, results obtained in Study 3 nicely extended findings emanating from Studies 1 and 2. First, our findings again supported $\mathrm{H} 1$ and $\mathrm{H} 3$, suggesting that persons with disability are devalued on warmth. This phenomenon emerged using a de-contextualized experimental procedure (control condition), as well as when providing a richer social context (work condition). Moreover, in line with $\mathrm{H} 2$, our results clearly demonstrated that persons with disability are associated with a lack of competence only when a work context was previously activated. This general prejudice, derogation on warmth as well as derogation on competence, also appear when focusing on the disability prime condition, supporting $\mathrm{H} 1 \mathrm{a}, \mathrm{H} 2 \mathrm{a}$, and $\mathrm{H} 3 \mathrm{a}$. In sum, negative implicit evaluation on warmth does not require any specific context, while negative evaluation on competence only manifests itself in competencerelevant situations, such as work environment. Taken together, these results give us a better understanding of why persons with disability are especially discriminated in the workplace.

\section{General Discussion}

Persons with disability have been consistently found to be associated with a high level of warmth, but a low level of competence, regardless of whether the context of judgment is general or specific, such as a work environment (Fiske et al., 2002; Louvet, 2007; Louvet et al., 2009; Rohmer \& Louvet, 2012). Negative evaluations toward persons with disability on competence are in line with discriminatory behaviors against these persons, especially in the workplace.
Positive evaluations on warmth could be based on the motivation to appear unprejudiced which leads individuals to overcompensate low ratings on competence by high ratings on warmth (Cambon et al., 2014). In fact, negative attitudes toward persons with disability could be unacceptable in our society, because these persons are a strongly normatively protected group (Dambrun \& Guimond, 2004). If this is the case, these positive evaluations would not manifest themselves when assessing implicit attitudes, assumed to be outside of awareness and intentional control. In order to test this assumption, two different priming procedures were used in this work to assess implicit stereotyping against persons with disability: conceptual priming (Study 1) and evaluative priming (Studies 2 and 3). Furthermore, insofar as persons with disability are especially discriminated in the workplace, a second aim was to analyze implicit prejudice and stereotyping against persons with disability when activating a work context (Study 3). We hypothesized that disability would be particularly associated with a lack of competence when a competence-relevant context is activated (work context). As expected, our results revealed important discrepancies with explicit stereotyping generally observed in the literature (Fiske et al., 2002; Louvet et al., 2009). Whereas persons with disability are generally stereotyped as warm at an explicit level, they were systematically associated in our results with low warmth at an implicit level. This result is in line with the assumption that an overcompensation strategy may be responsible for the positive evaluation of persons with disability on warmth at the explicit level (Dambrun \& Guimond, 2004; Fazio et al., 1995). Furthermore, our results showed that persons with disability are associated with low competence only when priming a work context. These findings are consistent with previous research suggesting that implicit stereotypes are sensitive to changes in the situational context (Casper, Rothermund, \& Wentura, 2010; Wittenbrink et al., 2001). These authors found that automatic associations between social categories (e.g., "Arabs") and negative words (e.g., "cancer") or stereotypical attributes (e.g., 
"terrorist") were facilitated only when specific contexts were previously presented, in which these associations were relevant (e.g., a gang incident or an airport). They also nicely corroborate the hypothesis suggested by Abele and Bruckmüller (2011) that competence gains in relevance depending on the situation at hand, whereas warmth dominates social judgment as the default in most situations.

Taken together, our results support the assumption that disability activates implicit stereotyping: persons with disability are not only associated with antipathy, but also with incompetence within a work context. Insofar as both dimensions show similar effects one might presume that general attitudes are responsible for these effects. In other words, disability might activate general negativity rather than specific devaluation on warmth and competence. However, we posit that negative evaluations on both dimensions cannot be reduced to general antipathy for several reasons. First, results are very similar with both evaluative and conceptual priming. Wittenbrink et al. (2001) clearly demonstrated that conceptual priming is sensitive to valenced items only if they are stereotypic of the primed group. Consequently, the effects cannot be explained only by general evaluation. Of course, we cannot guarantee that evaluation is totally eliminated from the process, but in this case, it is stereotypic evaluation and not general evaluation. Second insofar as context exerted a moderating influence on implicit information processing, one might presume that disability is not simply associated with general negativity. To further explore this fundamental distinction between stereotyping and general prejudice, it would be interesting to introduce general positive and negative targets (e.g., "love," "holidays," vs. "disease," “murder") in our priming paradigm in order to demonstrate that general attitudes are not entirely responsible for the effects observed. Furthermore, insofar as the effects were primarily observed when focusing on positive traits and the disability prime, the without-disability condition and negative traits may be dropped in future research.

From a more applied perspective, our results suggesting that persons with disability are disliked and devaluated on competence in a work context, could explain why policies promoting equal rights and opportunities to persons with disability fail to ensure social participation and especially employment among these persons. Further research should advance to improve understanding of this important question of automaticity in social judgments and how to curb negative attitudes towards persons with disability.

\section{Funding}

This research received no specific grant from any funding agency in the public, commercial, or not-for-profit sectors.

\section{Notes}

1. Fonds pour l'Insertion des Personnes Handicapées dans la Fonction Publique (FIPHFP) and AGEnce Française pour l'Insertion des Personnes Handicapées (AGEFIPH) are French associations working for the professional integration of people with disabilities.

2. A potential limitation of this disability prime could be the ambiguity of the construct activated: persons in a wheelchair, persons with disability, or even disability itself. However, previous research suggested that the type of disability has little effect on competence and warmth judgments (e.g., Fiske et al., 2002; Rohmer \& Louvet, 2011). Additionally, previous research suggested that it is difficult to clearly disentangle disability from persons with disability (Stiker, 2004). It is obvious that a person in a wheelchair simultaneously evokes disabled persons and disability. This confusion is clearly illustrated in the validated Disability Attitude Implicit Association Test (DA-IAT): the categories used to classify words and symbols are respectively "disability" and “nondisabled" (Pruett \& Chan, 2006).

\section{References}

Abele, A. E., \& Bruckmüller, S. (2011). The bigger one of the Big Two? Preferential processing of communal information. Journal of Experimental Social Psychology, 47, 935-948. doi:10.1016/j. jesp.2011.03.028

Abele, A. E., Uchronski, M., Suitner, C., \& Wojciszke, B. (2008). Towards an operationalization of the fundamental dimensions of agency and communion: Trait content ratings in five countries considering valence 
and frequency of word occurrence. European Journal of Social Psychology, 38, 1202-1217. doi:10.1002/ ejsp. 575

Bell, B. S., \& Klein, K. J. (2001). Effects of disability, gender, and job level on ratings of job applicants. Rehabilitation Psychology, 46, 229-246. doi:10.1037/0090-5550.46.3.229

Ball, P., Monaco, G., \& Schmeling, J. (2005). Disability and diversity in Fortune 100 companies. Behavioral Science Law, 23, 97-121. doi:10.1002/ bsl.629

Bayle, N. (2002). Determinants of the employers' behaviour towards disabled workers. Les Cabiers Internationaux de Psychologie Sociale, 54, 84-101.

Boccato, G., Cortes, B. P., Demoulin, S., \& Leyens, J. P. (2007). The automaticity of infra-humanization. European Journal of Social Psychology, 37, 987-999. doi:10.1002/ejsp.412

Boman, T., Kjellberg, A., Danermark, B., \& Boman, E. (2015). Employment opportunities for persons with different types of disability. European Journal of Disability Research, 9, 116-129. doi:10.1016/j. alter.2014.11.003

Cambon, L., Yzerbyt, V., \& Yakimova, S. (2014). Compensation in intergroup relations: An investigation of its structural and strategic foundations. British Journal of Social Psychology, 54, 140-158. doi:10.1111/bjso.12067

Casper, C., Rothermund, K., \& Wentura, D. (2010). Automatic stereotype activation is context dependent. Social Psychology, 41, 131-136. doi:10.1027/1864-9335/a000019

Chen, S., Ma, L., \& Zhang, J. X. (2011). Chinese undergraduates' explicit and implicit attitudes toward persons with disabilities. Rehabilitation Counseling Bulletin, 55, 38-45. doi:10.1177/0034355211410705

Christman, L. A., \& Slaten, B. L. (1991). Attitudes toward people with disabilities and judgments of employment potentials. Perceptual and Motor Skills, 72, 467-475. doi:10.2466/PMS.72.2.467-475

Colella, A., De Nisi, A. S., \& Varma, A. (1998). The impact of ratee's disability on performance judgments and choice as partner. Journal of Applied Psychology, 83, 102-111. doi:10.1037/00219010.83.1.102

Crandall, C. S., Eshleman, A., \& O'Brien, L. (2002). Social norms and the expression and suppression of prejudice: The struggle for internalization. Journal of Personality and Social Psychology, 82, 359-378. doi:10.1037/0022-3514.82.3.359
Cuddy, A. J. C., Fiske, S. T., \& Glick, P. (2007). The BIAS map: Behaviors from intergroup affect and stereotypes. Journal of Personality and Social Psychology, 92, 631-648. doi:1037/0022-3514.92.4.631

Cuddy, A. J. C., Glick, P., \& Beninger, A. (2011).The dynamics of warmth and competence judgments and their outcomes in organizations. Research in Organizational Behavior, 31, 73-98. doi:10.1016/j. riob.2011.10.004

Cumming, G. (2014). The new statistics: Why and how. Psychological Science, 25, 7-29. doi:10.1177/0956797613504966

Dambrun, M., \& Guimond, S. (2004). Implicit and explicit measures of prejudice and stereotyping: Do they assess the same underlying knowledge structure. European Journal of Social Psychology, 34, 663-676. doi:10.1002/ejsp.223

Devine, P. G. (1989). Stereotypes and prejudice: Their automatic and controlled components. Journal of Personality and Social Psychology, 56, 5-18. doi:10.1037/0022-3514.56.1.5

De Wit, B., \& Kinoshita, S. (2014). The masked semantic priming effect is task dependent: Reconsidering the automatic spreading activation. Journal of Experimental Psychology: Learning, Memory, and Cognition, 40, 1733-1744. doi:10.1037/xlm0000074

Dijksterhuis, A., \& Bargh, J. A. (2001). The perceptionbehavior expressway: Automatic effects of social perception on social behaviour. Advances in Experimental Social Psychology, 33, 1-40. doi:10.1016/ S0065-2601(01)80003-4

Dionne, C. D., Gainforth, H. L., O’Malley, D. A., \& Latimer-Cheung, A. E. (2013). Examining implicit attitudes towards exercisers with a physical disability. The Scientific World Journal. Retrieved from http://dx.doi.org/10.1155/2013/621596

Dovidio, J. F., Kawakami, K., Johnson, C., Johnson, B., \& Howard, A. (1997). On the nature of prejudice: Automatic and controlled processes. Journal of Experimental Social Psychology, 33, 510-540. doi:10.1006/jesp.1997.1331

Enea-Drapeau, C., Carlier, M., \& Huguet, P. (2012). Tracking subtle stereotypes of children with trisomy 21: From facial-feature-based to implicit stereotyping. PLoS ONE, 7, e34369. doi:10.1371/ journal.pone.0034369

Fazio, R. H. (2001). On the automatic activation of associated evaluations: An overview. Cognition and Emotion, 15, 115-141. doi:10.1080/02699930125908

Fazio, R. H., Jackson, J. R., Dunton, B. C., \& Williams, C. J. (1995). Variability in automatic activation 
as an unobtrusive measure of racial attitudes: A bona fide pipeline? Journal of Personality and Social Psychology, 69, 1013-1027. doi:10.1037/00223514.69.6.1013

Fichten, C. S., \& Amsel, R. (1986). Trait attributions about college students with a physical disability: Circumplex analyses and methodological issues. Journal of Applied Social Psychology, 16, 410-427. doi:10.1111/j.1559-1816.1986.tb01149.x

Fiske, S. T., Cuddy, A. J., Glick, P., \& Xu, J. (2002). A model of (often mixed) stereotype content: Competence and warmth respectively follow from perceived status and competition. Journal of Personality and Social Psychology, 82, 878-902. doi:10.1037//0022-3514.82.6.878

Gouvier, W. D., Sytsma-Jordan, S., \& Mayville, S. (2003). Patterns of discrimination in hiring job applicants with disabilities: The role of disability type, job complexity, and public contact. Rehabilitation Psychology, 48, 175-181. doi:10.1037/00905550.48.3.175

Greenwald, A. G., \& Banaji, M. R. (1995). Implicit social cognition: Attitudes, self-esteem, and stereotypes. Psychological Review, 102, 4-27. doi:10.1037/0033295X.102.1.4

Kervyn, N., Yzerbyt, V., Judd, C. M., \& Nunes, A. (2009). A question of compensation: The social life of fundamental dimensions of social perception. Journal of Personality and Social Psychology, 96, 828-842. doi:10.1037/a0013320

Kurita, T., \& Kusumi, T. (2009). Implicit and explicit attitudes toward people with disabilities and effects of the internal and external sources of motivation to moderating prejudice. Psychologia, 52, 253-260. doi:10.2117/psysoc.2009.253

Lo, S. H., \& Ville, I. (2013). The "employability" of disabled people in France: A labile and speculative notion to be tested against the empirical data from the 2008 "Handicap-Santé" study. European Journal of Disability Research, 7, 227-306. doi:10.1016/j.alter.2013.09.007

Louvet, E. (2007). Social judgment toward job applicants with disabilities: Perception of personal qualities and competences. Rehabilitation Psychology, 52, 297-303. doi:10.1037/0090-5550.52.3.297

Louvet, E., \& Rohmer, O. (2010). Are workers with disability perceived as competent? Psychologie $d u$ Travail et des Organisations, 16, 47-62.

Louvet, E., Rohmer, O., \& Dubois, N. (2009). Social judgment of people with a disability in the workplace: How to make a good impression on employers. Swiss Journal of Psychology, 68, 153-159. doi:10.1024/1421-0185.68.3.153

Nario-Redmond, M. R. (2010). Cultural stereotypes of disabled and non-disabled men and women: Consensus for global category representations and diagnostic domains. British Journal of Social Psychology, 49, 471-488. doi:10.1348/0144666 09X468411

Neely, J. H. (1977). Semantic priming and retrieval from lexical memory: Role of inhibitionless spreading activation and limited-capacity attention. Journal of Experimental Psychology: General, 106, 226-254. doi:10.3758/BF03213230

Oldmeadow, J. A., \& Fiske, S. T. (2010). Social status and the pursuit of positive social identity: Systematic domains of intergroup differentiation and discrimination for high- and low-status groups. Group Processes and Intergroup Relations, 13, 425-444. doi:10.1177/1368430209355650

Oswald, F. L., Mitchell, G., Blanton, H., Jaccard, J., \& Tetlock, P. E. (2013). Predicting ethnic and racial discrimination: A meta-analysis of IAT criterion studies. Journal of Personality and Social Psychology, 105, 171-192. doi:10.1037/a0032734

Ozawa, A., \& Yaeda, J. (2007). Employer attitudes toward employing persons with psychiatric disability in Japan. Journal of Vocational Rehabilitation, 26, 105-113.

Peris, T. S., Teachman, B. A., \& Nosek, B. A. (2008). Implicit and explicit stigma of mental illness. The Journal of Nervous and Mental Disease, 196, 752-760. doi:10.1097/NMD.0b013e3181879dfd

Pruett, S. R., \& Chan, F. (2006). The development and psychometric validation of the Disability Attitude Implicit Association Test. Rehabilitation Psychology, 51, 202-213. doi:10.1037/0090-5550.51.3.202

Ravaud, J. F., Madiot, B., \& Ville, I. (1992). Discrimination towards disabled people seeking employment. Social Science and Medicine, 35, 951-958. doi:10.1016/0277-9536(92)90234-H

Robey, K. L., Beckley, L., \& Kirschner, L. B. (2006). Implicit infantilizing attitudes about disability. Journal of Developmental and Physical Disabilities, 18 , 441-453. doi:10.1007/s10882-006-9027-3

Rohmer, O., \& Louvet, E. (2009). Describing persons with disability: Salience of disability, gender, and ethnicity. Rehabilitation Psychology, 54, 76-82. doi:10.1037/a0014445

Rohmer, O., \& Louvet, E. (2011). Stereotype content of disability subgroups: Testing predictions of the fundamental dimensions of social judgment. 
L'Année Psychologique, 111, 69-85. doi:10.4074/ S0003503311001035

Rohmer, O., \& Louvet, E. (2012). Implicit measures of the stereotype content associated with disability. British Journal of Social Psychology, 51, 732-740. doi:10.1111/j.2044-8309.2011.02087.x

Rüsch, N., Corrigan, P. W., Todd, A. R., \& Bodenhausen, G. V. (2011). Automatic stereotyping against people with schizophrenia, schizoaffective and affective disorders. Psychiatry Research, 186, 34-39. doi:10.1016/j.psychres.2010.08.024

Stiker, H. J. (2004). About the difference. La Nowvelle Revue de l'AIS, 27, 191-198.

Thomas, A., Vaughn, D., \& Doyle, A. (2007). Implementation of a computer based Implicit Association Test as a measure of attitudes toward individuals with disabilities. Journal of Rehabilitation, 73, 3-14. doi:10.1177/0034355211403008

Wade, M. L., \& Brewer, M. B. (2006). The structure of female subgroups: An exploration of ambivalent stereotypes. Sex Roles, 54, 753-765. doi:10.1007/ s11199-006-9043-x

Watermeyer, B. (2012). Is it possible to create a politically engaged, contextual psychology of disability? Disability \& Society, 27, 161-174. doi:10.1080/096 87599.2011.644928
Weinberg, N. (1976). Social stereotyping of the physically handicapped. Rehabilitation Psychology, 23, 115-124. doi:10.1037/h0090911

Winance, M., Ville, I., \& Ravaud, J. F. (2007). Disability policies in France: Changes and tensions between the category-based. Universalist and personalized approaches. Scandinavian Journal of Disability Research, 9, 160-181. doi:10.1080/15017410701680795

Wittenbrink, B., Judd, C. M., \& Park, B. (2001). Spontaneous prejudice in context: Variability in automatically activated attitudes. Journal of Personality and Social Psychology, 81, 815-827. doi:10.1037/00223514.81.5.815

Wittenbrink, B., \& Schwarz, N. (Eds.). (2007). Implicit measures of attitudes. New York, NY: Guilford Press.

World Health Organization (WHO). (2011). World report on disability. Geneva, Switzerland: Author.

Ybarra, O., Chan, E., Park, H., Burnstein, E., Monin, B., \& Stanik, C. (2008). Life's recurring challenges and the fundamental dimensions: An integration and its implications for cultural differences and similarities. European Journal of Social Psychology, 38, 1083-1092. doi:10.1002/ ejsp.559 